\title{
La recuperación del Palacio de Pedro I de Torrijos (Toledo): Una apuesta de la administración local
}

Jesús Nicolás Torres Camacho ${ }^{a}$ y Fernando Aceituno Luengo ${ }^{a}$

${ }^{a}$ Dpto. Cultura y Turismo. Ayuntamiento de Torrijos, Plaza de San Gil, n. 7, CP. 45500 Torrijos (Toledo). culturayturismo@torrijos.es

\begin{abstract}
Resumen
El Palacio de Pedro I de Torrijos (Toledo) constituye un interesante ejemplo de recuperación monumental efectuada por la administración local. La apuesta del Ayuntamiento de Torrijos se encontró con enormes dificultades desde sus intentos de venta por la congregación religiosa que lo habitó durante siglos, hasta litigios por su propiedad. En la actualidad el Palacio de Pedro I es la sede administrativa y cultural de la localidad, así como un recurso turístico de enorme potencial.
\end{abstract}

Palabras clave: Palacio de Pedro I, Torrijos, concepcionistas franciscanas, recuperación, administración local.

\begin{abstract}
The Palace of Pedro I de Torrijos (Toledo) constitutes an interesting example of monumental recovery carried out by the local administration. The bet of the City Council of Torrijos met with enormous difficulties from its attempts to sell it by the religious congregation that inhabited it for centuries, to litigation over its property. Currently the Pedro I Palace is the administrative and cultural headquarters of the town, as well as a tourist resource of enormous potential.
\end{abstract}

Keywords: Palace of Pedro I, Torrijos, Franciscan conceptionists, recovery, local administration. 


\section{Introducción}

El Palacio de Pedro I de Torrijos (Toledo) se conforma como un monumento complejo en volúmenes, cronología y funcionalidad, en íntima relación con otras edificaciones del monarca, como las de Astudillo, Tordesillas, Carmona y Sevilla (Almagro, 2013). Diferentes fases y estratificaciones históricas se han sumando en un monumento creado, recreado y restaurado a lo largo del tiempo.

Sus orígenes como residencia real se remontan a la figura del rey Pedro I de Castilla en el siglo XIV, continuador de la obra iniciada por su padre, Alfonso XI que mandó su construcción para conmemorar la Batalla del Salado. A finales del siglo XV la acción del matrimonio Cárdenas-Enríquez, personajes ilustres de la Corte de los Reyes Católicos, representó la trasmutación del espacio monárquico al nobiliario. Las trazas fueron adaptadas al gusto renacentista y la muerte prematura del segundogénito, Alonso de Cárdenas, conllevó un importante cambio de uso ordenado por su madre, Teresa Enríquez. En 1507 se adecúa el palacio como convento de clausura, fundado por Enríquez, bajo la advocación de las Concepcionistas Franciscanas. La dotación económica y rentista que dejó a la congregación tras su muerte resultó crucial en el devenir histórico del bien y su función religiosa prevaleció experimentando modificaciones hasta su abandono en el último tercio del siglo XX (Cera, 2019). Tras un periodo de inacción se producirá la compra del espacio por parte de la administración local, desarrollándose un proceso que culminará con la transformación de este elemento patrimonial en la sede administrativa y cultural del Ayuntamiento de Torrijos.

Existe escasa documentación que arroje luz sobre las vicisitudes de este bien patrimonial, centrándose las fuentes existentes en su devenir histórico vinculado a sus moradores y en su conformación como sede local (Longobardo y de la Peña, 2001). El objetivo principal de este trabajo es analizar el proceso documental de recuperación del Palacio de Pedro I localizado en el municipio de Torrijos (Toledo). La metodología empleada parte de una visión interdisciplinar bajo un enfoque patrimonial, basado en el análisis de diversa documentación histórica, de archivo, normativas, legislación, etc., que nos permiten constatar la recuperación del propio bien.

\section{La declaración BIC: antecedentes y consecuencias}

El testamento de Teresa Enríquez, fallecida el 4 de marzo 1529, determinó la economía del convento durante varios siglos hasta llegar al XIX, marcado por el proceso de desamortización eclesiástica. La comunidad, que a principios del siglo XVII contaba con 40 profesas (Briones, Corroto y Maquedano, 2006), tuvo que adaptarse al contexto de inestabilidad política, económica y social, y se vieron sometidas a la subasta de rentas de las numeras propiedades de labranza y huertas que poseyeron ${ }^{1}$ (tabla 1 ).

Tabla 1. Arbitrios de amortización anuncio núm. 229 a virtud del Real Decreto de venta de fincas. Boletín Oficial de la Provincia del 8 de julio de 1838

\begin{tabular}{|c|c|c|}
\hline Extensión & Localización & Precio \\
\hline 19 fanegas & Cerro de Palo & En venta 11.580 rs. \\
\hline 10 fanegas & Mangadas & En venta 6.050 rs. En renta 131 rs. y 160 mrs. \\
\hline 7 fanegas & Unqueras & En venta 5.631 rs. En renta 169 rs. y 6 mrs. \\
\hline 7 fanegas & Camino del Carpio & En venta 4.239 rs. En renta 127 rs. y 5 mrs. \\
\hline 5 fanegas & Lomas de la Villa & En venta 2.528 rs. En renta 75 rs. y 28 mrs. \\
\hline 5 fanegas & Paredes & En venta 3.028 rs. En renta 90 rs. y 28 mrs. \\
\hline 1 fanega y 6 celemines & El Cerrojo & En venta 758 rs. En renta 22 rs y 24 mrs. \\
\hline 3 fanegas y 6 celemines & Camino de la Mata & En venta 2.119 rs. En renta 63 rs y 19 mrs. \\
\hline 1 fanega y 9 celemines & La Quemadilla & En venta 880 rs. En renta 26 rs. y 13 mrs. \\
\hline 2 fanegas y 6 celemines & Pico de la Buena Obra & En venta 2.010 rs. En renta 60 rs. y 10 mrs. \\
\hline 2 fanegas y 6 celemines & El Horno & En venta 1.510 rs. En renta 45 rs. y 10 mrs. \\
\hline 2 fanegas y 6 celemines & La Ermita & En venta 2.760 rs. En renta 82 rs. y $26 \mathrm{mrs}$. \\
\hline
\end{tabular}

\footnotetext{
${ }^{1}$ Archivo Histórico Provincial. 33701/007. Signatura H-1986/007
} 


\begin{tabular}{|c|c|c|}
\hline 7 fanegas & El Sendero & En venta 4.939 rs. En renta 148 rs. y 5 mrs. \\
\hline 3 fanegas & Los Guindales & En venta 4.939 rs. En renta 63 rs. y 10 mrs. \\
\hline 2 fanegas & Las Presas & En venta 1.611 rs. En renta 48 rs. y 11 mrs. \\
\hline 5 fanegas & El Viso & En venta 3.028 rs. En renta 90 rs. y $28 \mathrm{mrs}$. \\
\hline 2 fanegas & Manzanillo & En venta 1.311 rs. En renta 39 rs. y $11 \mathrm{mrs}$. \\
\hline 2 fanegas & La Mata & En venta 1.211 rs. En renta 36 rs. y 11 mrs. \\
\hline 4 fanegas & Pedro Lopa Grande & En venta 2.822 rs. En renta 84 rs. y 22 mrs. \\
\hline 1 fanega y 6 celemines & Pedro Lopa Chica & En venta 1.058 rs. En renta 31 rs. y 25 mrs. \\
\hline 7 fanegas & Suerte de Mula & En venta 4239 rs. En renta 127 rs y 6 mrs. \\
\hline 7 fanegas & Suerte de Mula & En renta 4239 rs. En venta 127 rs. y 5 mrs. \\
\hline 10 fanegas & Los Llanos & En venta 6.050 rs. En renta 181 rs. y $11 \mathrm{mrs}$. \\
\hline 8 fanegas & El Pico & En venta 6.044 rs. En renta 181 rs. y $11 \mathrm{mrs}$. \\
\hline
\end{tabular}

Sin embargo, gracias a la cartografía de Ibáñez Ibero (1881) podemos observar el reflejo de su capacidad económica en su conjunto conventual (Fig. 1). Cuatro grandes claustros-patios articularon la vida doméstica y religiosa de la congregación. De entre todos ellos destacó el claustro porticado de doble galería de corte renacentista, en esos momentos con un pozo central. Por su tamaño destaca el huerto con estanque y pozo, y el jardín para la meditación, representando el cuarto espacio el conjunto de patios y corrales de las zonas de almacenamiento y viviendas de capellán y demandaderas. Los aproximadamente $4.000 \mathrm{~m}^{2}$ también albergaron la iglesia y el coro (ampliación del siglo XVIII), diversos altares, refectorio, cocinas, repostería, horno y las celdas.

Las grandes dimensiones del convento junto a la reducción profesas y rentas, hicieron insostenible su mantenimiento. En 1934 se recaudaban fondos para reparar sus tejados a través de veladas benéficas organizadas por las catequistas de la parroquia ${ }^{2}$, pero a pesar de las iniciativas se llegó a un punto de no retorno en la década de 1960.

El estado de conservación del espacio obligó a su abandono en 1970, mientras se incoaba expediente para su declaración como monumento. De forma paralela la congregación visualizaba las posibilidades económicas de su venta que fueron frenadas por la administración. El 29 de mayo de 1970 la Dirección General de Bellas Artes prohibió cualquier interés especulativo por parte de la congregación a pesar de las continuas presiones de la abadesa, Sor Inmaculada López de Lama ${ }^{3}$. Finalmente, el 5 de febrero de 1981, se dio carpetazo definitivo a todo este proceso mediante la declaración de Monumento Histórico-Artístico Nacional bajo la denominación de Convento de las RR.VV. Madres Concepcionistas de Torrijos ${ }^{4}$, Bien de Interés Cultural (BIC), en función de la Ley 16/1985, de 25 de junio, del Patrimonio Histórico Español.

Llegar a esta situación fue un camino complejo y lleno de contradicciones. Por una parte, la abadesa, llegó a solicitar una intervención de urgencia a la Dirección General de Patrimonio Artístico, Archivos y Museos. En esta misiva expuso que, después de abandonar el edificio por el estado de ruina, habían acudido a diversos organismos del Estado, sin que ninguno lo calificara con el más mínimo interés. Y que, para sorpresa de la congregación, tras su abandono el 27 de febrero de 1970 quedó incoado expediente de declaración monumental, siendo invitadas en enero de 1975 a revisar el expediente en el Casón del Buen Retiro y plantear una solución. En esa visita pudieron comprobar, en palabras de la abadesa, las inexactitudes de los trámites de declaración, que recogían la presencia de elementos artísticos, como yeserías, inexistentes. Por eso, ante los riesgos que palidecía el edificio como hundimientos, vandalismo, incendios, la abadesa propuso dos soluciones: una, ofrecer la venta al Estado por 15 millones de pesetas con la posibilidad de que enviasen peritos para su consideración, y dos, la anulación del expediente de declaración para permitir su venta a una inmobiliaria $^{5}$.

\footnotetext{
${ }^{2}$ El Castellano. 08/02/1934.

${ }^{3}$ Archivo Regional de Castilla-La Mancha. Caja 178619.

${ }^{4}$ Boletín Oficial del Estado, núm. 66 (18-03-1981).

${ }^{5}$ Archivo Regional de Castilla-La Mancha. Caja 178619.
} 


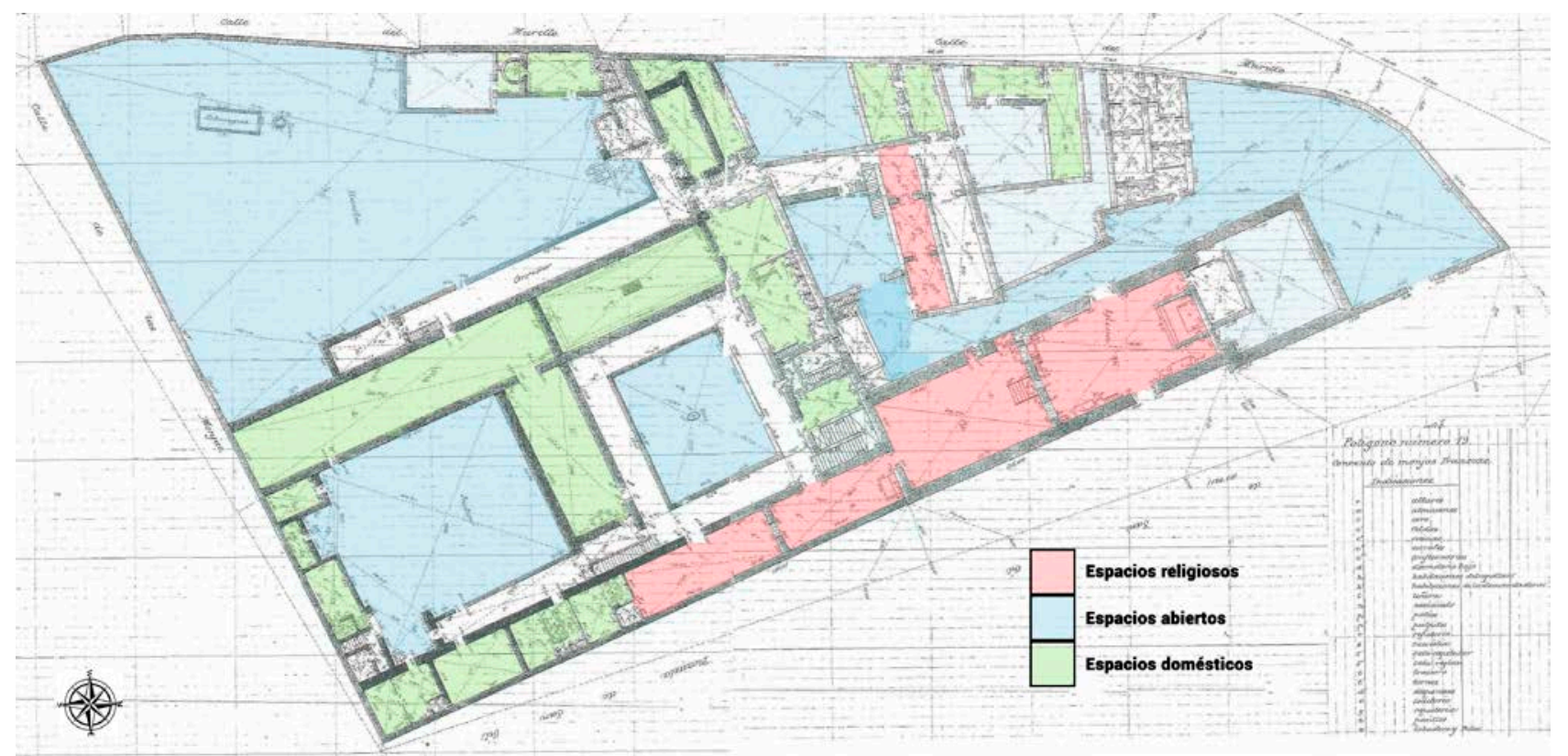

Fuente: Briones, Corroto y Maquedano (2006)

Fig. 1 Cartografía del Convento Franciscano elaborado por José García de la 8 Brigada y conformado por Ventura Pizcueta, aprobado por Ibáñez Ibero el 21/05/1881. E: 1/250. Modificado por los autores

Por otro lado, dentro del gobierno municipal existió un acalorado debate sobre qué hacer con el edificio. Las actas ordinarias en pleno muestran que para esas fechas se produjo la visita de Felipe A. Calvo y Calvo, catedrático de la Universidad Complutense de Madrid y de Bartolomé Escandell Bonet, decano de la Facultad de Filosofía y Letras de la Universidad de Alcalá de Henares. Ambos indicaron lo costoso que sería llevar a cabo las reparaciones pertinentes para su aprovechamiento por lo que sería más adecuado su derribo, y así se lo comunicarían a Javier Tussel, Director General del Patrimonio Artístico. De igual modo, un informe dirigido por el subdirector general de Planificación y Programación del Ministerio de Educación y Ciencia, transcrito del informe de la Unidad Técnica de Toledo, expuso los altos costes que podría conllevar la rehabilitación del espacio para su reaprovechamiento. Ante tal situación el teniente alcalde, Miguel Ángel Ruíz Ayúcar, defendió la importancia de conservar, conocer y divulgar el patrimonio local para darlo un uso social. Puso como ejemplo la pérdida irreparable del patrimonio de Torrijos de principios del siglo XX y que correspondía a cada uno de los ciudadanos evitar una nueva merma. El Ayuntamiento redactó un informe dirigido a Javier Tussel para que desde la Dirección General de Patrimonio Artístico se adoptase una única postura ${ }^{6}$. Este movimiento a nivel local desembocó en la declaración BIC y permitió despejar el camino de intereses especulativos y adoptar una postura favorable a la recuperación del espacio.

Conseguida la declaración, la siguiente problemática estuvo marcada por la falta de claridad en cuanto a sus legítimos propietarios. En 1984 la Duquesa de Maqueda, María Dolores Barón Osorio de Moscoso, heredera directa del primer Duque de Maqueda, Diego de Cárdenas y Enríquez, primogénito del matrimonio Cárdenas-Enríquez, inició una actividad procesal dirigida por el letrado Miguel Ángel García Brera, mediante la cual reclamaba la propiedad de la Casa de Maqueda sobre diversos inmuebles, entre los que se encontraba el viejo convento. Por ello interpuso una demanda reivindicatoria exponiendo que las monjas no tenían derecho ni a inscribir el edificio a su nombre ni, por supuesto, a venderlo, ya que únicamente tenían el derecho de uso y disfrute por lo que tras su abandono debía de volver a sus legítimos propietarios.

La defensa de la congregación religiosa se basó exclusivamente en el testamento de Teresa Enríquez. Según este ostentaban desde la fecha de su muerte (1529) su propiedad, y que, además, el antiguo palacio quedó fuera del mayorazgo, por tanto, desvinculado de la casa de Maqueda. En cuanto al proceso, se inició ante el Juzgado de Primera Instancia de Torrijos, que desestimó la demanda de la Duquesa. Se interpuso Recurso de Apelación que también fue

${ }^{6}$ Archivo Municipal de Torrijos. Signatura 1.1.2.03. 
desestimado, y finalmente acudieron al Tribunal Supremo que dictó sentencia definitiva y firme desestimando las pretensiones de la Duquesa. Firme la sentencia y pacificada la propiedad del Convento a favor de las Monjas se pudo llegar a un acuerdo para su venta al Ayuntamiento de Torrijos, previo rechazo al derecho de tanteo por parte del Estado y al beneplácito del Arzobispado de Toledo a autorizar una venta eclesiástica.

\section{La Escuela Taller Trastamara}

Esta iniciativa del Ayuntamiento de Torrijos, junto con la Diputación de Toledo, se enmarcó dentro del Programa Nacional de Escuelas Taller y Casas de Oficios (1985), que se inició como un proyecto experimental que pronto dio buenos frutos de su utilidad, regulándose por Orden del Ministerio de Trabajo y Seguridad Social de 29 marzo de 1988. Se definió en un primer momento como "programas públicos de empleo-formación que tienen como finalidad la inserción de jóvenes desempleados menores de veinticinco años. A través de su cualificación en alternancia con la práctica profesional en ocupaciones relacionadas con la recuperación o promoción del patrimonio artístico, histórico, cultural o natural; la rehabilitación de entornos urbanos o del medio ambiente: la mejora de las condiciones de vida de las ciudades, así como cualquier otra actividad de utilidad pública o de interés general y social que permita la inserción a través de la profesionalización y experiencia de los participantes" 7 .

En el caso de Torrijos, el ente promotor de este proyecto fue la Diputación de Toledo, integrada en este programa nacional desde 1989. Su preocupación era hacer frente a una problemática heredada hasta nuestros días, el éxodo de los entornos rurales a los urbanos debido a falta de oportunidades. Sus líneas de actuación fueron en dos direcciones:

- Garantizar el funcionamiento correcto de la Escuela Taller, asumiendo los gastos no subvencionables, y aportar los medios y el personal desde Toledo.

- Dotar a la escuela del carácter comarcal para que sean varios los pueblos que puedan beneficiarse de estas políticas desde el punto de vista de alumnos como por obras que pueda realizar la escuela.

El patrimonio de Torrijos se vio doblemente beneficiado de este proyecto. Uno, el propio caso que nos ocupa, y dos, la Escuela-Taller (E.T.) Garcilaso de la Vega de Toledo, que se encargó de la restauración del coro del siglo XVI de la Colegiata del Santísimo Sacramento de Torrijos.

En el caso de la Escuela-Taller Trastamara I, posteriormente tuvo una segunda fase de actuación, bajo el nombre Escuela-Taller Trastamara II, estaba compuesta por las especialidades de carpintería, cerrajería y forja, instalaciones eléctricas, solados y revocos, albañilería y cantería, con un total de 44 alumnos (Fig. 2). El Ayuntamiento se comprometió a garantizar la inserción laboral del 92\% de los alumnos participantes. Además, se aprobó en pleno el 27 de diciembre de 1995 un presupuesto para el año siguiente de 1.500 .000 pesetas destinado exclusivamente a la Escuela Taller para financiar los gastos que no cubriesen las distintas subvenciones solicitadas. Un día antes se pidió a la Diputación provincial una subvención económica de 127.882 .930 pesetas. Finalmente, a través del interventor en funciones de la Diputación de Toledo se concedieron 85 millones de pesetas para iniciar el proyecto desde el 11 de junio de 1996 hasta el 10 de junio de 1998.

Los servicios realizados por parte de la E.T. consistieron en la rehabilitación integral de una de las alas del convento franciscano, que pasaría a denominarse Palacio Pedro I, que constaba de cuatro plantas y una galería exterior porticada, ocupando una superficie de actuación de unos $1.061 \mathrm{~m}^{2}$ del total de casi $4.000 \mathrm{~m}^{2}$ que disponía el conjunto (las sucesivas ventas de las monjas a pequeños propietarios redujeron casi en $1.000 \mathrm{~m}^{2}$ la superficie). Todo este entorno se proyectó como el futuro centro cultural y administrativo de Torrijos, con servicios de auditórium cubierto, auditórium al aire libre, biblioteca, salas de conferencias, oficina, exposiciones, talleres de pintura, etc.

La E.T. tenía previsto actuar sobre el ala contigua al auditórium de verano, reconstruyendo la galería porticada en estado de ruina, rehaciendo el muro de cerramiento y el de separación entre zonas, interviniendo en la zona designada como zona de oficinas, que constaba de cuatro plantas, aula de conferencias, aseos y camerinos del auditórium y porche (Fig. 3). La obra se preveía como un elemento a terminar, constando de instalaciones, carpintería, forjas-cerrajerías,

${ }^{7}$ Boletín Oficial del Estado, núm. 77 (30-03-1985). 
trabajos de canterías, albañilerías, yesos, solados y alicatados. Por otra parte, los gastos derivados a los materiales necesarios para habilitar un local de impartición de las clases y las oficinas iban a cuenta del propio Ayuntamiento.

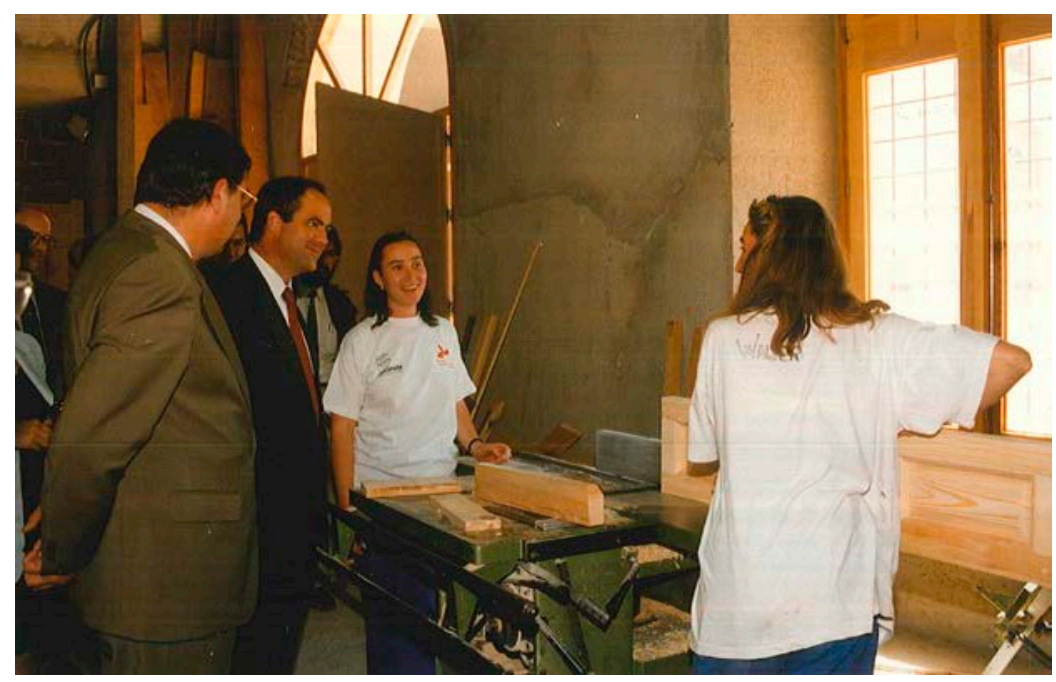

Fuente: Archivo Municipal de Torrijos. Signatura B-0006

Fig. 2 Visita de José Bono, presidente de la Junta de Comunidades de Castilla - La Mancha (1983-2004), a los trabajos realizados por la E.T. Trastamara en el Palacio de Pedro I. Año 1997

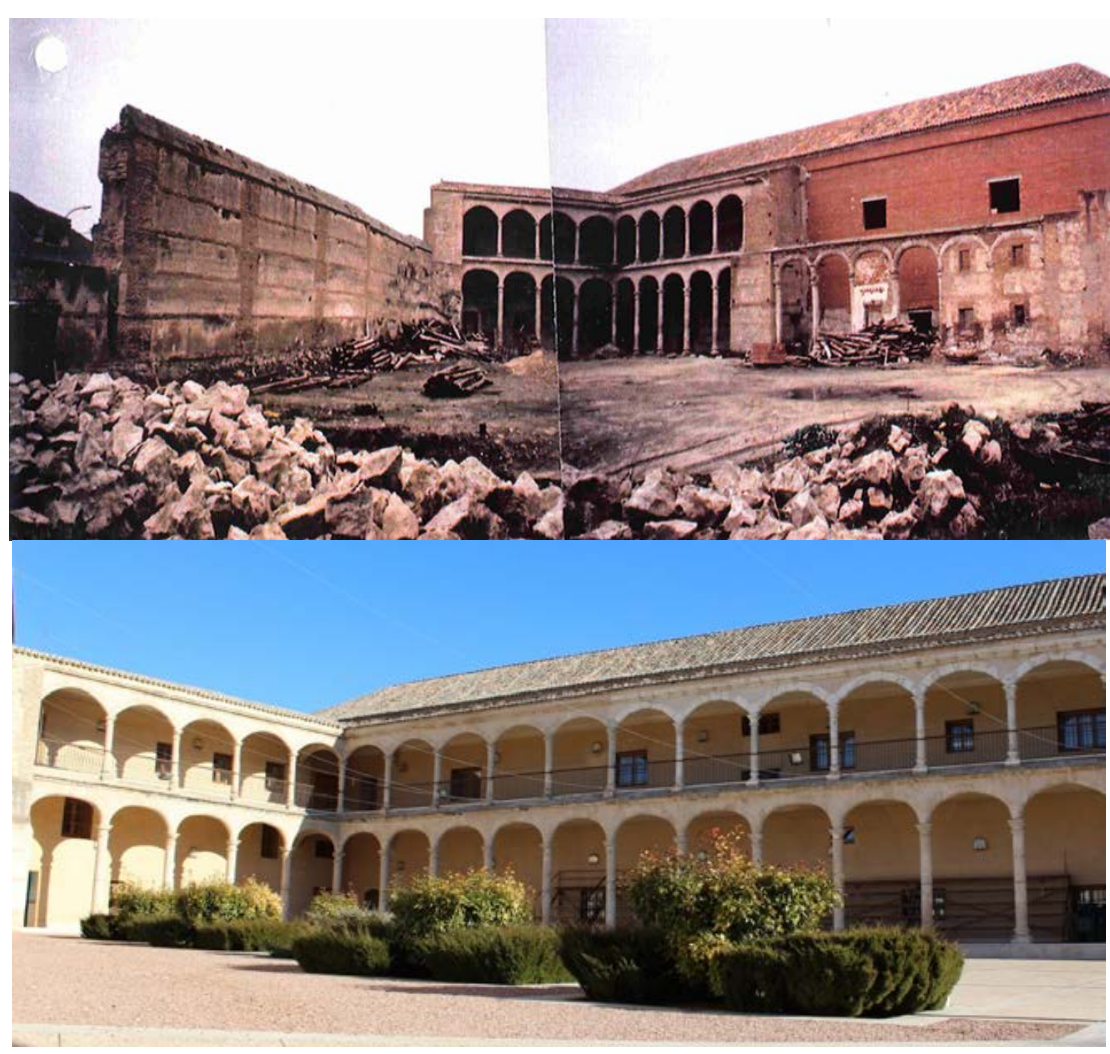

Fuente: Ayuntamiento de Torrijos

Fig. 3 Comparativa del claustro exterior del Palacio de Pedro I antes y después de la actuación de la E.T. Trastamara. Años 1992-2019

La actuación de la escuela se rigió en base a la legislación del momento, aplicando unos criterios específicos que respetasen las implicaciones que traía consigo una declaración BIC del edificio. Para ello el organismo local pidió un 
informe sobre el estado del inmueble a la empresa Arcion S.A., recogido íntegramente por Longobardo y de la Peña (2001).

De forma simultánea el informe arqueológico, realizado en 1992 por los Servicios de Arqueología de la Diputación de Toledo, recogía el interés histórico-artístico del inmueble en torno a tres periodos. Sirvió de base a los arquitectos encargados del proyecto. El primero de estos periodos históricos del edificio respondía a sus orígenes bajomedievales, limitándose a escasa cimentación compuesta por restos de un muro de mampostería inconexos al edificio actual y estructuras subterráneas de características constructivas diferentes. De la época fundacional del convento, siglo XVI, se mantiene la articulación primitiva en torno a tres grandes patios-claustros con sus respectivos arcos carpaneles y columnas toscanas. De un momento un poco anterior, correspondiente al periodo de adecuación del palacio como dote de boda al segundogénito del matrimonio Cárdenas-Enríquez son las trazas mudéjares de los yesos y el gran artesonado aparecido. Finalmente, los restos con interés histórico-artístico más reciente corresponden al espacio que forman unas pinturas murales de la cripta, el coro y la iglesia del convento, una ampliación de los siglos XVII-XVIII que llegó vacía en cuanto a bienes muebles decorativos por todo el proceso descrito anteriormente.

El único aspecto de la restauración que se le escapaba a la E.T. fue el tratamiento de los restos de pinturas murales aparecidos. La propia composición de la escuela no recogía en ningún apartado esas labores. Para ello fue necesaria la intervención posterior de talleres especializados en este cometido entre los años 2000-2007. Fueron dos, el primero, integrado por Carmen Palomo, Isabel Sela, Marisol Núñez (Fig. 4) y, el segundo, la empresa Gargola Conservación de Obras de Arte S.L. (Fig. 5), cuyo firmante del proyecto fue Javier Encinas Monje ${ }^{8}$.
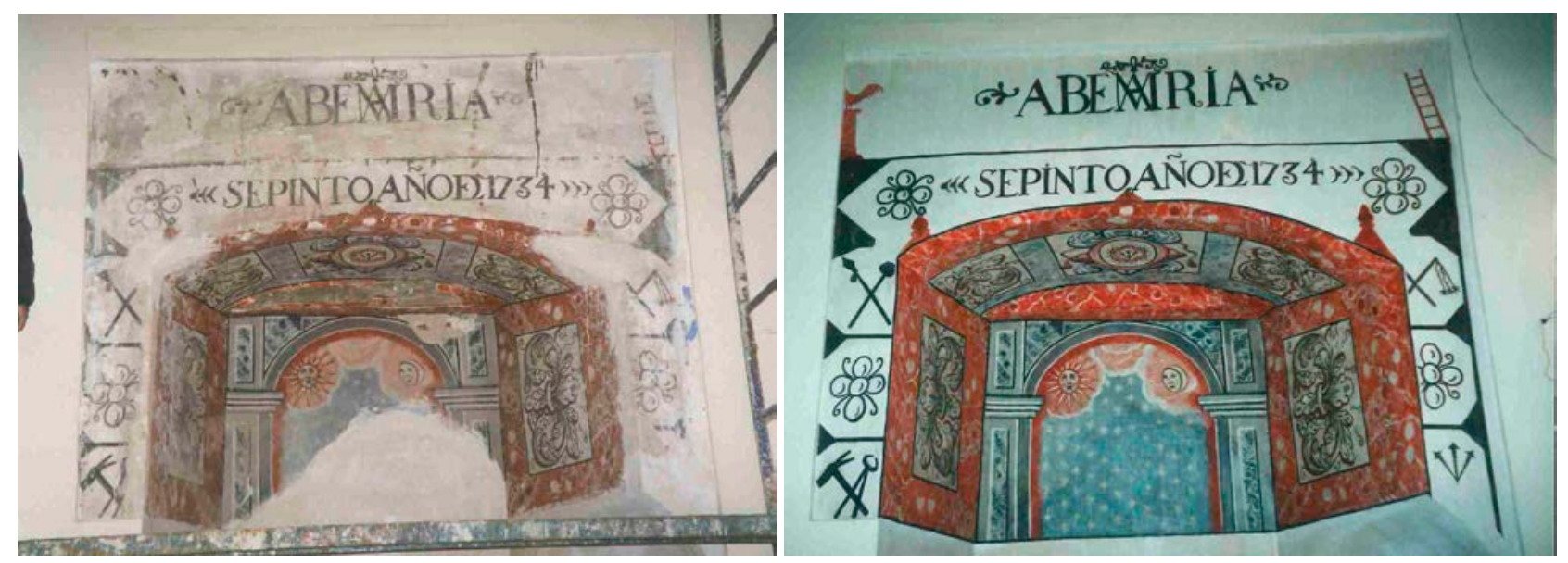

Fuente: Carmen Palomo

Fig. 4 Restauración de las pinturas murales de la zona de cripta, actual Servicio de Atención al Ciudadano. Año 2000

El primer taller fue el encargado de restaurar los restos murales aparecidos en un hornacina de la zona dedicada a cripta del convento, que representaban los instrumentos de la Pasión de Cristo. Formaban parte de un conjunto mayor, según reflejaron las catas realizadas por los servicios de arqueología de la diputación. Las pinturas de estas armas Christi fueron encontradas en relativamente buen estado de conservación, pudiendo incluso apreciar su fecha de elaboración, 1734.

Por otra parte, el segundo se encargó de la restauración de las pinturas de la antigua sala del refectorio del convento, actual oficina de turismo, que constaba de varios elementos. El primero de ellos, una cenefa de textos en latín relativos a la consagración del pan y el vino. Se encontraban en una zona complicada, ya que era el punto de unión entre la pared y el alfarje de par y nudillo, también conservado, para la instalación del circuito eléctrico. Justo en un nivel inferior apareció una serie de escudos franciscanos con los estigmas de la flagelación de Cristo, flanqueados por angelotes, y dispuestos por todo el espacio rectangular. Por último, en uno de los testeros de la sala, se descubrió una interesante representación de la Última Cena, cuyas trazas aparecieron en buen estado aunque matéricamente se apreciaban faltas de pigmentación. Se desconoce la autoría de ambas pinturas, dejándose abiertas líneas de investigaciones futuras.

\footnotetext{
${ }^{8}$ Archivo Municipal de Torrijos. Caja sin clasificar.
} 


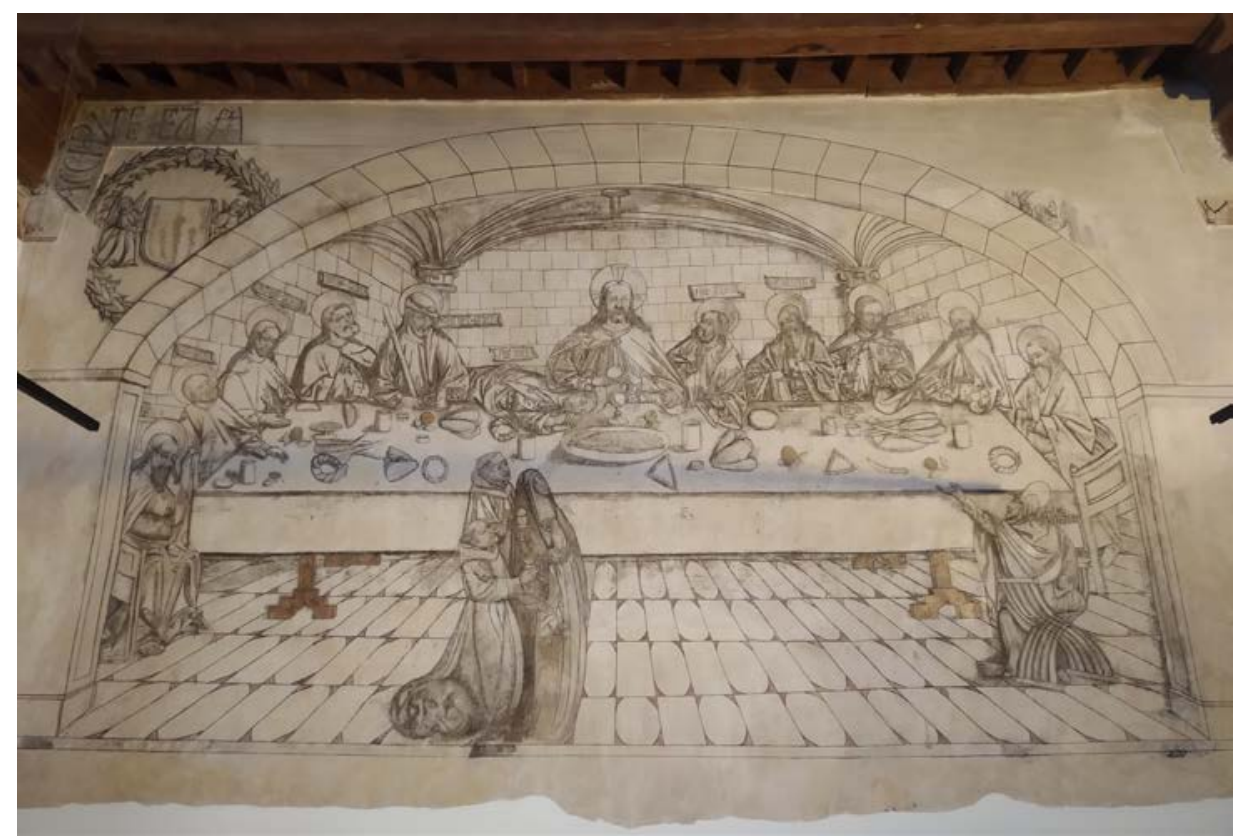

Fuente: Ayuntamiento de Torrijos

Fig. 5 Estado actual de las pinturas del refectorio, actual oficina de turismo de Torrijos. Año 2019

Finalmente, el Ayuntamiento elabora un "Acta de terminación de obras" con fecha del 25 de febrero de 1999 en el que se hace constar de forma oficial la finalización de este ingente proyecto que empezó a gestarse desde el momento en el que es abandonado y se abre expediente para su protección. En 2001 se terminó de trasladar las dependencias del antiguo consistorio municipal inaugurándose en el "renovado" Palacio de Pedro I su nueva sede (Fig. 6). De tal forma, se dio respuesta a una serie de cuestiones ligadas a la conservación del patrimonio histórico y sus valores de uso para proyectar un espacio con una finalidad socio-cultural.

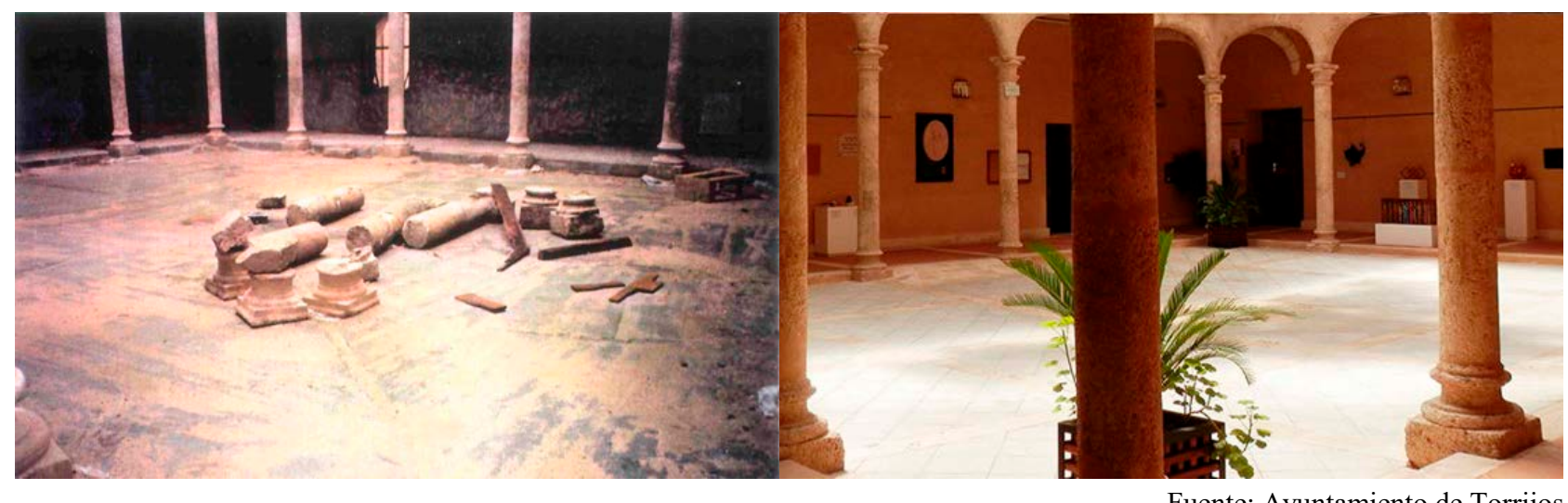

Fuente: Ayuntamiento de Torrijos

Fig. 6 Comparativa del claustro porticado principal del Palacio de Pedro I antes y después de la actuación de la E.T. Trastamara. Años 1992-2019

\section{EI Palacio de Pedro I como contenedor cultural y administrativo}

La conservación del nuestro patrimonio cultural material e inmaterial ha cobrado importancia a escala local. Las progresivas normativas que regula su protección son fundamentales para impulsar que a partir de su preservación, pueda convertirse en una oportunidad de desarrollo y diversificación económica, por ejemplo a través de la cultura y el turismo. Nuestro patrimonio juega un destacado papel en la construcción de un futuro común, qué se selecciona y cómo se protege es determinante. Estamos acostumbrados a las erróneas decisiones que se toman en materia patrimonial a escala local, sin embargo, este trabajo ha pretendido reflejar la difícil tarea que ejerció el Ayuntamiento de Torrijos al 
apostar por la recuperación del viejo Convento Franciscano y devolver a la sociedad el Palacio de Pedro I. Esas decisiones afectan hoy a la memoria colectiva, a la identidad, a las prácticas sociales, es un recuerdo del pasado del que se pueden extraer lecciones que aprender (Capel, 2014).

Dos décadas después de la reconversión del Palacio de Pedro I en Ayuntamiento de la localidad de Torrijos, podemos hacer balance del arduo proceso que ha permitido rescatar de la piqueta un conjunto monumental de enorme valor patrimonial, ensombrecido turísticamente por la majestuosa Colegiata del Santísimo Sacramento y, en ocasiones, escasamente apreciado por su propia población al localizarse en un área de carácter marginal.

La recuperación ha contribuido a revitalizar urbana y socialmente todo el contexto territorial del Palacio de Pedro I hasta llegar a la declaración de su entorno como BIC en $2010^{9}$. Alrededor de él se articulan todos los valores del patrimonio. Su valor de uso responde a la capacidad de satisfacer las necesidades administrativas y culturales de la población; su valor material compuesto por todos los elementos de interés histórico-artísticos que se salvaron gracias a esta actuación (claustros, artesonados, yeserías, etc.) y que generan interés para su visita; y su valor simbólico, histórico y emotivo, que responden a la identidad local que se ha configurado en torno a este espacio como consecuencia de su devenir histórico y de la participación de población local en su recuperación.

Desde el punto de vista administrativo acoge actualmente numerosos servicios: servicio de atención al ciudadano, deportes, juventud, intervención, secretaría, servicios técnicos, así como los propios del gobierno de la localidad, alcaldía, concejalías, salas de reuniones y el salón de plenos, coronado por la armadura de par y nudillo del siglo XVI. En cuanto al carácter cultural alberga la biblioteca municipal, la oficina de turismo, el archivo municipal y el auditorio con capacidad para 335 butacas, que ofrece una amplia oferta de espectáculos teatrales y musicales dirigidos a todas las edades. Por lo tanto cubre un servicio a nivel comarcal, que contribuye, en línea con los principios de la E.T., a evitar el éxodo rural, en este caso a través de la generación de una oferta cultura y ocio amplia, sin necesidad de desplazarse a las ciudades más cercanas (Toledo, Talavera de la Reina y Madrid).

El Palacio de Pedro I está presente en la nueva Web de Cultura de la Junta de Comunidades de Castilla-La Mancha (https://cultura.castillalamancha.es) dentro de los "Yacimientos y Monumentos visitables". Hoy en día se ha convertido en un elemento imprescindible en la visita a Torrijos. El turista puede comprobar a través del recorrido por claustros y dependencias el proceso de recuperación efectuado por la administración local, muestra paradigmática de la apuesta de un pueblo por salvar su patrimonio $\mathrm{y}$, en consecuencia, su identidad.

\section{Referencias}

Almagro, A. (2013). Los palacios de Pedro I. La arquitectura al servicio del poder. Anales de historia del arte, 2, 25-49. Recuperado de https://revistas.ucm.es/index.php/ANHA/article/view/42830/40686

Biblioteca Virtual de Castilla-La Mancha (Centro de Estudios de Castilla-La Mancha), El Castellano 8/2/1934, https://ceclmdigital2.uclm.es

Boletín Oficial del Estado, https://boe.es

Briones, L. B., Corroto, J., y Maquedano, B. (2006). Las líneas del patrimonio histórico, III: planos topográficos del siglo XIX de la provincia de Toledo. Toledo: Diputación Provincial de Toledo.

Capel, H. (2014). El patrimonio: la construcción del pasado y del futuro. Barcelona: Ediciones El Serbal.

Cera Brea, M. (2019). La Loca del Sacramento, los Cárdenas y Torrijos. En F. Marías y M. Cera (Dirs.), La Colegiata de Torrijos (pp. 37-51). Toledo: Consejería de Educación, Cultura y Deportes. Servicio de Publicaciones.

Longobardo, J., y de la Peña, J. (2001). Los Palacios de Torrijos. Torrijos: Gráficas Torrijos S.L.

Portal de Cultura de Castilla-La Mancha., https://cultura.castillalamancha.es

\footnotetext{
${ }_{9}^{9}$ Documento Oficial de Castilla-La Mancha, núm. 212 (03-11-2010).
} 